\title{
Fabrication of hydrogel based nanocomposite scaffold containing bioactive glass nanoparticles for myocardial tissue engineering
}

Zahra Barabadi ${ }^{\mathrm{a}}$, Mahmoud Azami ${ }^{\mathrm{a}}$, Esmaeel Sharifi ${ }^{\mathrm{b}, \mathrm{a}}$, Roya Karimi ${ }^{\mathrm{a}}$, Nasrin Lotfibakhshaiesh ${ }^{\mathrm{a}}$, Reza Roozafzoon $^{\mathrm{a}}$, Mohammad Taghi Joghataeic, Jafar Ai ${ }^{\mathrm{a}, \mathrm{d}}$

${ }^{a}$ Department of Tissue Engineering and Applied Cell Sciences, School of Advanced Technologies in Medicine, Tehran University of Medical Sciences, Tehran, Iran

${ }^{\mathrm{b}}$ Cellular and Molecular Research Center, Shahrekord University of Medical Sciences, Shahrekord, Iran ${ }^{\mathrm{c}}$ Anatomy Department, Iran University of Medical Sciences, Tehran, Iran

${ }^{\mathrm{d} B r a i n}$ and Spinal Injury Research Center, Tehran University of Medical Sciences, Tehran, Iran

Corresponding author address: Department of Tissue Engineering and Applied Cell Sciences, School of Advanced Technologies in Medicine, Tehran University of Medical Sciences, Tehran, Iran. Tel: 0098214352110, Email address: jafar_ai@tums.ac.ir 


\begin{abstract}
Selecting suitable cell sources and angiogenesis induction are two important issues in myocardial tissue engineering. Human endometrial stromal cells (EnSCs) have been introduced as an abundant and easily available resource in regenerative medicine. Bioactive glass is an agent that induces angiogenesis and has been studied in some experiments. The aim of this study was to investigate in vitro differentiation capacity of endometrial stem cells into cardiomyocyte lineage and to evaluate capability of bioactive glass nanoparticles toward EnSCs differentiation into endothelial lineage and angiogenesis on hydrogel scaffold. Our findings suggests that endometrial stem cells could be programmed into cardiomyocyte linage and considered a suitable cell source for myocardial regeneration. This experiment also revealed that inclusion of bioactive glass nanoparticles in hydrogel scaffold could improve angiogenesis through differentiating EnSCs toward endothelial lineage and increasing level of vascular endothelial growth factor secretion.
\end{abstract}

Keyword: Hydrogel, nanocomposite scaffold, bioactive glass, myocardial tissue engineering

\title{
1. Introduction:
}

Cardiovascular disease is the leading cause of death worldwide. Myocardial infarction (MI) is caused by blockage of the arteries that supply the myocardium. The human cardiomyocytes do not have the ability to regenerate after myocardial infarction. Subsequently, they are gradually replaced by fibroblasts in the infarcted area that leads to the formation of scar tissue and cardiac dysfunction [1]. Common clinical interventions for the treatment of MI include conservative measures such as lifestyle modifications and medications or more invasive measures such as cardiac catheterization and surgery. These interventions cannot lead to the 
regeneration of lost myocardial tissue [2]. Cell transplantation into the infarcted zone has been recently studied as an alternative approach. There has been limited success of cell transplantation because of cell migration and loss due to harsh environment in this area. Another problem is weak integration of injected cells with the native cardiomyocytes. Cell transplantation can be improved by tissue engineering techniques. With this approach, the cells could be effectively integrated to the infarcted area by placing them in a protective matrix and thus preventing cell migration and loss [3].

Hydrogels have frequently been studied for myocardial tissue engineering as bioactive substances that mimic biochemical and biomechanical microenvironment in order to provide a supportive matrix for cell delivery. These materials not only preserve the transplanted cells but also act as physical support for the thin wall of the heart following MI [2].

One main problem in myocardial tissue engineering is the lack of functional vessels which ultimately leads to low survival rate of engineered tissues/injected cells [3]. As a result, angiogenesis potential should be one of the most important characteristics of a scaffold used in this field. Angiogenesis has some major benefits including delivering oxygen and nutrients to the tissues, removing waste products and the potential to increase engineered construct dimensions. Bioactive glasses, which are mainly used in hard tissue engineering, are bioactive materials mostly containing $\mathrm{SiO}_{2}, \mathrm{Na}_{2} \mathrm{O}, \mathrm{P}_{2} \mathrm{O}_{5}$, and $\mathrm{CaO}$. There are different types of bioactive glasses with the ability to bind to soft and hard tissues [4]. It has been demonstrated that these materials can stimulate fibroblasts to secrete large amounts of angiogenic factors which may lead to the infiltration of vessels into the engineered scaffold [5-7].

Selection of an appropriate cell source is an important issue for cell therapy in patients suffering from heart failure. Many cell types are being investigated for this purpose, such as myoblasts, cardiomyocytes, bone marrow stem cells, embryonic stem cells, adipose tissue- 
derived stem cells, cardiac progenitor cells and induced pluripotent stem cells (IPS), each one having its own advantages and disadvantages [8-14].

Presence of stem cells has been demonstrated in the endometrial layer of the uterus. Some features of these endometrial stem cells (ENSCs) are ease of access, purer population versus bone marrow stem cells, differentiation potential into different cell lines, high proliferation rate, angiogenesis potential through secretion of large amounts of VEGF, immune-modulatory properties and nearly $1.25 \%$ clonogenic activity. They also maintain a normal karyotype after 68 times of cell division [15]. These features make them a suitable candidate for cell therapy. In this study, EnSCs were used as a cell source to be differentiated into cardiomyocytes according to a modified protocol with a different concentration of 5-Azacytidine (5-AZA).A suitable scaffold was designed for myocardial tissue engineering. For evaluation of the angiogenic effect of the added bioglass, we assessed the differentiation capacity of undifferentiated cells within heterogeneous population of treated cells toward endothelial lineage on scaffold.

\section{Methods:}

\subsection{Preparation of BG Nanoparticles}

The sol-gel prepared BG consisting of $45 \% \mathrm{SiO}_{2}, 24.5 \% \mathrm{Cao}, 24.5 \% \mathrm{Na}_{2} \mathrm{O}$ and $6 \% \mathrm{P}_{2} \mathrm{O}_{5} \mathrm{~mol} \%$ was synthesized. The following procedure was done for BG synthesis: $7.27 \mathrm{~g}$ Tetraethylorthosilicate (TEOS: $\mathrm{C}_{8} \mathrm{H}_{20} \mathrm{O}_{4} \mathrm{Si}$, Merck) was added into $1 \mathrm{~mL}$ of $1 \mathrm{M} \mathrm{HCl}$ (Merck); the mixture was allowed to react for $1 \mathrm{~h}$ for the acidic hydrolysis of TEOS to proceed almost to completion. The following reagents were added in sequence allowing $45 \mathrm{~min}$ for each reagent to react completely under stirring condition: $1.58 \mathrm{~g}$ triethyl phosphate (TEP: $\mathrm{C}_{6} \mathrm{H}_{15} \mathrm{O}_{4} \mathrm{P}, \mathrm{Merck}$ ), $4.49 \mathrm{~g}$ calcium nitrate $\left(\mathrm{Ca}\left(\mathrm{NO}_{3}\right)_{2} \cdot 4 \mathrm{H}_{2} \mathrm{O}\right.$, Merck) and 3.23g sodium nitrate $\left(\mathrm{NaNO}_{3}\right.$, Merck). Then, mixing was continued for $1 \mathrm{~h}$ to allow completion of the hydrolysis reaction. The 
solutions were cast in a cylindrical Teflon container and kept sealed for 10 days at room temperature to allow the hydrolysis and polycondensation reaction to take place until the gel was formed. The gel was heated at $70^{\circ} \mathrm{C}$ for $24 \mathrm{~h}$. The water was removed and a small hole was inserted in the lid to allow the leakage of gases while heating the gel to $120^{\circ} \mathrm{C}$ for an additional day to remove all water. Subsequently, the dry powder was heated up to $760^{\circ} \mathrm{C}$ without staying time at this temperature with the heating rate of $8^{\circ} \mathrm{C} / \mathrm{min}$ with for water, alkoxide removing and nitrated decomposition. Higher heating rate rather than other reports [16] and zero staying time for stabilization were selected to avoid formation of larger crystals. Finally the product was milled for $10 \mathrm{~h}$ by planetary mill (SVD15IG5-1, LG Company) to achieve bioactive glass nanoparticles.

\subsection{Scaffold Fabrication}

Two types of scaffold were fabricated for this research: gelatin-collagen hydrogel (Gel/Col)(Merck, microbiology grade, catalog number 104,070) with the ratio of $9 / 1$ and gelatin collagen bioactive glass nanocomposite(Gel/Col/BG).For this purpose, collagen was added to deionized water containing $50 \mathrm{mM}$ acetic acid, and gelatin was added to deionized water in a stirrer at $40^{\circ} \mathrm{C}$.After $1 \mathrm{~h}$, collagen and gelatin solutions were mixed to make a $10 \%$ (w/v) solution. In the case of GEL/COL/BG nanocomposites, $0.1 \mathrm{wt} \% \mathrm{BG}$ was added to the above mixture and heated up to $40^{\circ} \mathrm{C}$ and stirred for 1 hour. Finally, to reduce the biodegradation rate and enhance the mechanical properties, the scaffolds were cross-linked by addition of genipin (Sigma, USA) with the ratio of $0.01 \mathrm{gr} / 1 \mathrm{gr}$ GEL/COL. These mixtures were poured into plastic Petri dishes and allowed to solidify at room temperature for $24 \mathrm{~h}$. Two-step freezing was done at $-20^{\circ} \mathrm{C}$ for $16 \mathrm{~h}$ followed by $-80^{\circ} \mathrm{C}$ for $5 \mathrm{~h}$. In order to produce $3 \mathrm{D}$ porous structure through sublimation, frozen scaffolds were moved to the freeze dryer at $-57^{\circ} \mathrm{C}$ and 
0.05 mbar for $24 \mathrm{~h}$. After freeze drying, samples were carefully washed with ethanol for $2 \mathrm{~h}$ and then in deionized distilled water for several times to remove the remnant of genipin.

\subsection{Engineering Characterization for BG nanoparticles and prepared Scaffold}

\subsubsection{Thermal Analysis: Differential scanning calorimetry and thermogravimetric analysis (DSC-TGA)}

To find the proper heat-treatment temperature of the $\mathrm{BG}$, the thermal behavior of the $\mathrm{BG}$ before heat-treatment was studied by TGA and DSC analyses. These analyses were done using Shimadzu TGA-50 apparatus, under air atmosphere, starting from room temperature up to $1000^{\circ} \mathrm{C}$ with the heating rate of $10^{\circ} \mathrm{C} / \mathrm{min}$.

\subsubsection{Fourier Transform Infrared (FTIR) Spectroscopy}

Fourier transformed infrared analysis was performed to identify the nature of the chemical bonds between atoms. IR analysis of BG nanoparticles was carried out by Bomem MB 100 spectrometer. For this aim, $1 \mathrm{mg}$ of the powder samples were carefully mixed with $300 \mathrm{mg}$ of $\mathrm{KBr}$ (infrared grade) and made into a pellet under vacuum. Then the pellets were analyzed in the range of $400-2000 \mathrm{~cm}^{-1}$ with $4-\mathrm{cm}^{-1}$ resolution averaging 120 scans.

This technique was also carried out for chemical characterization of fabricated scaffolds. For this purpose, fabricated scaffold samples were analyzed in the range of $400-4000 \mathrm{~cm}^{-1}$.

\subsubsection{X-ray Diffraction Analysis}

The BG nanoparticles were analyzed by XRD with (Philips X'Pert-MPD system) diffractometer. This instrument works with voltage and current settings of $40 \mathrm{kV}$ and $40 \mathrm{~mA}$ respectively and uses $\mathrm{Cu}-\mathrm{K} \alpha$ radiation $(1.5418 \AA$ ). For qualitative analysis, XRD diagrams were recorded in the interval $10^{\circ} \leq 2 \theta \leq 100^{\circ}$ at scan speed of $2^{\circ} / \mathrm{min}$. 


\subsubsection{Scanning Electron Microscopy (SEM)}

The shape and size of the synthesized BG nanoparticles were evaluated using SEM. For this aim BG nanoparticles were coated with a thin layer of Gold $(\mathrm{Au})$ by sputtering (EMITECH K450X, England) and observed by scanning electron microscopy (TESCSN-MIRA, USA Inc.). Porosity and microstructure of the fabricated scaffolds were assessed using scanning electron microscope (SEM-Philips XL30) operated at the acceleration voltage of $15 \mathrm{kV}$.

\subsubsection{Porosity and Pore Size Measurement}

Scaffold pore size measurement was done using Image $\mathbf{J}$ software on SEM images taken from several cross sections of the scaffolds. For this aim, surface area of pores in each section was divided to the whole area of the picture and reported as an average value for each scaffold [17][18]. Mean random 40-50 pores diameter from each image was considered as scaffold pore size.

\subsection{Evaluation of cell viability and proliferation on the scaffold}

MTT assay was performed to evaluate cytotoxicity and biocompatibility of the scaffolds. The number of 104 L929cellswere cultured in triplicate on each group of scaffolds in a 24 -well culture plate and incubated at $37^{\circ} \mathrm{C}, 5 \% \mathrm{CO} 2$ with Dulbecco's modified Eagle's medium (DMEM)(GIBCO; Invitrogen Pvt Ltd., Australia) supplemented with 10\% fetal bovine serum (FBS) (In vitro Technologies, Australia). After 24, 48 and 72h, $100 \mu \mathrm{L}$ of MTT solution $\left(5 \mathrm{mg} / \mathrm{ml}\right.$ in DMEM) was added to each well and the plates were incubated at $37^{\circ} \mathrm{C}$ for $4 \mathrm{~h}$. Then, supernatant was removed and $100 \mu \mathrm{L}$ of DMSO was added and the resulting supernatant was transferred to 96 well plates. The absorbance was measured at $570 \mathrm{~nm}$ on a micro plate reader (BioTek Instruments, USA). Cells seeded in tissue culture polystyrene plates were used 
as control. Finally the cell viability (\%) was considered as a percentage of OD of cells on scaffolds relative to $2 \mathrm{D}$ control cells.

\subsection{Cell Attachment on the Scaffolds}

Two days post cell seeding, scaffolds were rinsed 3 times with phosphate-buffered saline (PBS) and fixed for $1 \mathrm{~h}$ in $2.5 \%$ glutaraldehyde- $4 \%$ Paraformaldehyde in PBS at $4{ }^{\circ} \mathrm{C}$. Fixed samples were washed 3 times with PBS. Post-fixation was done through soaking scaffolds in $1 \%$ osmium tetroxide in PBS for 15 min. Finally, the scaffolds were dehydrated in a graded series of ethanol and dried at room temperature. Gold coated samples were examined using SEM.

In the other assay the cultured cells on the scaffolds were stained by $0.5 \mu \mathrm{g} / \mathrm{ml}$ of fluorescent DNA-binding dye, 4-6-diamidino-2-phenylindole (DAPI), for 5 min to confirm their presence on scaffold 15 days post cell seeding.

\subsection{Isolation of Endometrial Stem Cells and Differentiation into Cardiomyocytes}

Endometrial stromal Stem cells (EnScs) used in the present study were isolated after informed consent was obtained, according to the protocol that was previously published [19].These cells displayed all of the defining parameters of EnScs. Third passage cells with confluence about $60-70 \%$ were treated with basic fibroblast growth factor (bFGF) $5 \mathrm{ng} / \mathrm{ml}$ in DMEM/F12 culture medium containing 5\% FBS 24 hours. The culture media were replaced with differentiation media including IMDM/ F12 supplemented with 2\% horse serum, ITS $0.1 \%$, non-essential amino acids $0.1 \%$, pen/strep $1 \%$, glutamax $1 \%$ and 5-AZA at the concentration of $20 \mathrm{nM}$ (all from sigma) for three days. Then the cells were cultured in differentiation media without 5AZA for 3 weeks. During differentiation, cellular morphology was assessed using inverted microscope. 


\subsection{Immunocytochemistry Analysis}

Differentiation was evaluated with ICC for cardiac-specific proteins including Connexin 43(Con43), cardiac Troponin T (TnT), Sarcomeric $\alpha$-Actinin ( $\alpha$-actinin) and Desmin; as well as MYOD and CD31, which are skeletal myocyte specific protein and endothelial surface marker respectively. Post treatment cells were fixed with 4\% paraformaldehyde for 20 min at $4^{\circ} \mathrm{C}$, permeabilized with Triton $0.2 \%$ for $30 \mathrm{~min}$, blocked with BSA $1 \%$ for $45 \mathrm{~min}$ at room temperature, and incubated overnight at $4^{\circ} \mathrm{C}$ with primary antibodies for cTnT (Mouse monoclonal antibody; Abcam, USA, ab10214, 1:200), $\alpha$-Actinin (Rabbit polyclonal antibody; Abcam, USA, ab72592, 1:200), Con43 (Mouse monoclonal antibody; Abcam, USA, ab79010, 1:100), Desmin (Mouse monoclonal antibody; Abcam, USA, ab8976, 1:200) ,MYOD (Mouse monoclonal antibody; Abcam, USA, ab16148, 1:200) and CD31 (Rabbit polyclonal antibody; Abcam, USA, ab28364,1:200) diluted in blocking solution. The preparations were incubated with secondary antibodies (Alexa Fluor 594 donkey anti-mouse IgG, Gibco, USA, A-21203; Alexa Fluor 594 donkey anti-rabbit IgG, Gibco, USA, A21207, at a 1:500 dilution) for $2 \mathrm{~h}$ at room temperature. Nuclei were counterstained with DAPI (4', 6-diamidino-2-phenylindole; 1:1000; Sigma). Cells were examined using a fluorescent inverted microscope (Olympus, BX51, Japan).

\subsection{Quantitative Real-Time Reverse Transcription Polymerase Chain Reaction (qRT- PCR)}

Expression levels of cardiac specific genes including Desmin, $\alpha$-actinin, MHC, TnT were investigated in treated cells in 2D and 3D cultures compared with untreated using qRT-PCR. Total RNA from cells was extracted using the RNeasy Mini Kit (Qiagen, Valencia, USA), according to manufacturer's instructions. RNA quantity was assessed by ND-1000 
spectrophotometer (Nanodrop Technologies, Inc.). After DNase treatment, $2 \mu \mathrm{g}$ of total RNA was used for reverse transcription with the Prime Script 1st strand cDNA Synthesis Kit (TaKaRa, Japan). One microliter of synthesized cDNA used for RT-PCR and for real timePCR reaction with SYBR_Premix Ex Taq ${ }^{\mathrm{TM}}$ (TAKARA BIO, INK, Japan) and the detection was carried out in a CFX Real- Time PCR System (Biorad, USA). The reaction was performed according to following order; $5 \mathrm{~min}$ of $95^{\circ} \mathrm{C}$ for enzyme activation, initial denaturation for $13 \mathrm{~s}$ at $95^{\circ} \mathrm{C}$, annealing temperature for $30 \mathrm{~s}$ at $65^{\circ} \mathrm{C}$, and extension at $72^{\circ} \mathrm{C}$ for $30 \mathrm{~s}$, followed by 42 cycles with a final extension at $65^{\circ} \mathrm{C}$. The primer sequences are shown in Table 1. Related changes in gene expression were quantified using $\Delta \Delta \mathrm{CT}$ method and were normalized versus GAPDH.

\subsection{Cell Seeding on Scaffolds}

Prior to cell seeding, scaffolds were sterilized with immersion in the following solutions: overnight $70 \%$ ethanol for sterilization; penicillin, streptomycin, and amphotericin B (1\%) in PBS at $37^{\circ} \mathrm{C}$ for $24 \mathrm{~h}$ to prevent yeast growth, and culture medium to enhance cell attachment. $10^{5}$ treated cells which were a mixture of differentiated and non-differentiated cells were trypsinized and transferred to sterilized scaffolds in 24 well plates and incubated in DMEM supplemented with $5 \%$ fetal bovine serum (FBS) at $37^{\circ} \mathrm{C}$ in a humidified atmosphere of $5 \%$ $\mathrm{CO}_{2}$. Media were exchanged every 2-3 days.

\subsection{Immunohistochemical (IHC) Analysis}

By 15 days following cell seeding on scaffolds, IHC analysis was performed to detect differentiated cells using $\alpha$-actinin antibody andCD31as well for evidence of angiogenesis. Scaffolds were OCT embedded and transferred to $-80^{\circ} \mathrm{C}$ freezer. Frozen construct sections $(10$ $\mu \mathrm{m}$ ) were fixed with PFA $4 \%$ for $15 \mathrm{~min}$, incubated in $5 \% \mathrm{H}_{2} \mathrm{O}_{2}$ for $5 \mathrm{~min}$ in order to abolish 
endogenous peroxidase activity; blocking was done with $2.5 \%$ goat serum for 20 min. Constructs were then incubated with monoclonal antibody against $\alpha$-actinin overnight and polyclonal antibody against CD31 for 1 hour (both in 1:200 concentration) followed by incubation with biotinylated goat anti-rabbit antibody, addition of avidin-biotin-horse radish peroxidase complex, peroxidase substrate 3.3'-diaminobenzidine (DAB) and $\mathrm{H}_{2} \mathrm{O}_{2}$ to develop a brown reaction product. Cell nuclei were counterstained with hematoxylin. Photomicroscopy using Olympus BX51 documented the positive reactivity of staining.

\subsection{VEGF Secretion Measurement on the Scaffolds}

The amount of VEGF secreted by cells on scaffolds was analyzed using a human VEGF ELISA kit (R\&D Systems, Inc.). For this experiment, 14 days after cell seeding on scaffolds, supernatant was collected for 48 hours, spun down to remove cell debris and then stored in $-70^{\circ} \mathrm{C}$ freezer until analysis according to the manufacturer's instructions.

\subsection{Statistics}

Each experiment was repeated independently at least three times. Results are reported as mean \pm SD. Unpaired $T$ test and one-way analysis of variance (ANOVA) followed by Tukey's Post Hoc test were used to compare the means. All analyses were performed using SPSS 20.0 software. P-values of less than 0.05 were considered as statistically significant. 


\section{Results:}

\subsection{Bioactive glass Characterization}

\subsubsection{BG Nanoparticles Morphology Assessment}

SEM was used to assess the BG nanoparticles size and shape. The low and high magnifications of SEM micrographs of BG nanoparticles are presented in the appendix (Figure I). As shown in these micrographs, particle sizes are under $80 \mathrm{~nm}$ and they are spherical in shape.

\subsubsection{Thermal Analysis: Differential scanning calorimetry and thermogravimetric} analysis (DSC-TGA)

DSC and TGA analyses of the prepared glass gels were carried out to obtain proper temperature for final BG stabilization. The obtained result is shown in the appendix (Figure IIA). TGA shows a total $31 \%$ weight reduction divided in two main weight losses, the first at about $100-280^{\circ} \mathrm{c}$ and the last at $520-750^{\circ} \mathrm{c}$ which are due to departure of free water, $-\mathrm{OH}$, alkoxides groups and nitrates decomposition, respectively. These are in accordance with DSC curve showing endothermic peaks for water evaporation and nitrates decompositions at about 100,600 and $700^{\circ} \mathrm{c}$ and exothermic peaks at $250^{\circ}$ cindicatingcombustion of ethylic radicals. No significant weight loss was observed above $750^{\circ} \mathrm{c}$, also these curves confirmed that the residuals could be removed before $760{ }^{\circ} \mathrm{C}$, so this temperature is appropriate for a full stabilization of the structure.

\subsubsection{XRD of BG Nanoparticles}

XRD pattern of prepared BG nanoparticles by sol-gel method in this study is shown in the appendix (Figure IIB). This diffractogram shows that the produced BG has almost an amorphous structure. However, there are some small peaks which according to ICCD data base 
matched with that of combeite phase [20,21], a crystalline sodium-calcium-silicate phase $\left(\mathrm{Na}_{2} \mathrm{Ca}_{2} \mathrm{Si}_{3} \mathrm{O}_{9}, \mathrm{PDF} \# 075-1687\right)$.

\subsubsection{FTIR of BG Nanoparticles}

FTIR spectrum of synthesized BG nanoparticles (Appendix Figure IIC) confirms that the obtained powder has the structure of a bioglass [16,22,23]. Wave numbers with their relative bands are shown in appendix table (a) as well.

\subsection{Scaffold characterization}

\subsubsection{FTIR of Fabricated Scaffolds}

FTIR spectrum of GEL/COL scaffold exhibited a number of characteristic spectral bands related to collagen as shown in figures 1 and table 2 . Below $1000 \mathrm{~cm}^{-1}$, amide characterized peak were seen $[24,25]$. Similar pattern can be seen in BG included scaffold that means addition of $0.1 \%$ BG nanoparticles to hydrogels did not affect the FTIR pattern of related scaffolds.

\subsection{Evaluation of cell viability and proliferation on the scaffold}

With reference to the biocompatibility of the fabricated scaffold, cell proliferation and viability assays were carried out using MTT assay. Obtained results of MTT assay demonstrated that cell viability decreased in both scaffolds after $24 \mathrm{~h}$ culture compared with $2 \mathrm{D}$ control. But after $48 \mathrm{~h}$ there was an increase in cell number in both scaffolds. The same trend could be seen in the 72h culture. By the third day, Gel/Col/BG scaffold showed a significant $(\mathrm{p}<0.05)$ increase of cell number and viability in comparison with Gel/Col. BG included scaffolds showed better cell viability than GEL/COL scaffolds all the times; which may be related to released ions from BG nanoparticles, which affected the cell survival [26,27]. Results are shown in figure2. 


\subsection{Scaffold Morphology and Cell Attachment on the Scaffolds by SEM}

In this study, SEM was used to evaluate scaffolds' microstructure. To determine porosity, we used a simple method by means of Image J software and SEM images, obtained from different cross sections of the prepared scaffolds. The mean porosity of the samples was estimated to be $85 \%$. As it can be seen, addition of $0.1 \%$ BG nanoparticles to hydrogel scaffold did not affect pore aperture and porosity of the scaffolds. Micrographs captured from the top view of nanocomposites are shown in upper part of Figure 3. High porosity with open pore structure and a high degree of interconnectivity can be seen in these images.

SEM images show the morphology of cells cultured for 10 days on two types of prepared scaffolds (Middle part of Figure 3). Cells have been attached to the surface of both scaffolds and present a well spread morphology and extended filopodia.

Lower part of Figure 3 confirms the presence of cells on the scaffold surfaces and bulks as well, meaning that cells are infiltrated in scaffolds through interconnected pores.

\subsubsection{Pore Size Analysis}

Scaffold pore sizes ranged from under 100 up to $600 \mu \mathrm{m}$ with the mean pore diameter of about 365 and $381 \mu \mathrm{m}$ for Gel/Col and Gel/Col/BG scaffolds respectively. No significant difference was seen between these two types of scaffolds.

\subsection{Characterization of EnSes Derived Cardiomyocytes}

\subsubsection{Immunostaining Analysis of EnScs Derived Cardiomyocytes}

From morphological point of view, isolated endometrial cells before differentiation were fibroblast like $[28,29]$, but during differentiation process, the morphological changes were noted. At first they were long rod-like and then gradually joined together and formed a twisted 
network with some extensions at both sides of the cells (Figure 4). As seen in the ICC images (Figures 5,6), cells are positively stained for cardiac proteins Con 43, TnT, $\alpha$-Actinin and Desmin, whereas they are negative for skeletal muscle-specific protein MYOD and endothelial surface marker CD31.

\subsubsection{Gene Expression Analysis of Differentiated cells in 2D and 3D Cultures}

The real-time PCR analysis revealed that expression of cardiomyocytes specific genes including $\alpha$-actinin, cTnT, $\alpha$-MHC and Desmin were significantly up regulated in treated cells versus untreated EnSCs in 2D culture (Figure 7,8). There is no significant difference in gene expression profiles between cells grown on both scaffolds and treated cells in 2D culture. Results have been shown in figure 9.

\subsubsection{Immunohistochemical Staining}

IHC analysis for cardiac $\alpha$-sarcomeric actinin showed positive staining for both types of scaffolds. There was only CD31 positive staining on nanocomposite scaffold containing BG nanoparticles. Cells on the scaffolds were strongly stained for $\alpha$ - actinin but irregularly and less intensely for CD31 (Figure 9).

\subsubsection{VEGF Secretion Levels by Cells on Scaffolds}

The expression of VEGF was measured in supernatant of cultures of differentiated cells on $\mathrm{Gel} / \mathrm{Col} / \mathrm{BG}$ scaffold and compared to control. The results indicate that supernatant of cultures on $\mathrm{Gel} / \mathrm{Col} / \mathrm{BG}$ scaffold contained significantly higher amounts of VEGF compared to culture son $\mathrm{Gel} / \mathrm{Col}$ scaffold $(2.14$ folds, $\mathrm{P}<0.001)$. This finding indicates that $\mathrm{BG}$ inclusion in hydrogel scaffold triggers expression of VEGF and subsequently promotes angiogenesis [30]. It has been showed that influx of calcium ion through L-type voltage gated Calcium channels leads to sustained activation of Src kinase and its subsequent effects on membrane 
depolarization of retinal pigment epithelium and calcium influx leads to sustained VEGF secretion. We propose that the prolonged release of calcium from bioglass in our nanocomposite scaffold following gradually degradation of scaffold through the above mechanism may lead to elevation in VEGF secretion [31].

\section{Discussion}

It is known that an ideal scaffold used for tissue engineering should possess biocompatibility, homogenous microstructure, suitable porous structure and high porosity [23]. Scaffold porosity is necessary for ingrowth of cells and migration of vascular tissue [32]. Collagen and gelatin as natural, highly biocompatible materials have been frequently used for myocardial tissue engineering studies [33]. So we used their useful properties to have a favorable scaffold in this study. Present data shows that the fabricated biocompatible natural based scaffolds have highly porous structure with interconnected pores which is suitable for cell attachment, infiltration and angiogenesis [29]. Scaffold microstructure along with BG nanoparticles inclusion in scaffold led to increased secretion of VEGF from cells on scaffolds that can promote angiogenesis.

Many different types of stem cells have been used for cardiomyocyte differentiation in different studies, but so far little attention has been paid to endometrial stem cells for this purpose. Differentiation capacity of these cells toward different lineage such as osteoblast, adipoblast, oligodendrocyte progenitor cell and neuron have been investigated in some studies $[33,34]$. Rahimi et al used menstrual blood stem cells to be differentiated to cardiomyocytes and found higher differentiation potential of this cells toward cardiomyocytes compared with BMSCs [35].

There are different protocols to differentiate different stem cells toward cardiomyocyte lineage. 5-AZA cytidine has been frequently used in many studies for this purpose, but due to its toxic effect on cells, the applied concentration in most of cases has been very low, up to $10 \mathrm{nM}$ [36]. 
In this experiment, we modified the protocol designed by Smits et al which was applied for differentiation of human cardiomyocyte progenitor cells [37].Pretreatment with bFGF along with using $\mathrm{TGF}_{\beta}$ in our experiment led to very low cell toxicity even with higher concentration of 5-AZA (20nM). Both ICC images and real time PCR experiments together indicate highly increased expression of cardiac specific markers indicating the differentiation capability of EnSCs toward cardiomyocyte. This study showed that treated EnSCs acquired some features of human cardiomyocytes and confirmed the EnSCs stemness and differentiation potential; it also suggests that these kinds of cells could be considered as a suitable cell source for cell therapy in patients suffering from myocardial infarction. Additional electrophysiological evaluation and in vivo experiments are needed for further characterization of differentiated cells.

Others have reported the effect of BG on angiogenesis but present knowledge on BG effect on soft tissue is insufficient [6,7]. Day et al., reported a higher fibroblast proliferation and higher VEGF expression when cultured on bioglass coated polystyrene surfaces for $24 \mathrm{~h}$ [6]. The present study showed that BG nanoparticles' incorporation into hydrogel scaffold induces differentiation in EnSCs toward endothelial lineage and promotes angiogenesis via increasing VEGF secretion level.

\section{Conclusion}

Our data indicate that EnSCs can efficiently differentiate into cardiomyocytes. This study showed that incorporation of BG nanoparticles into hydrogel scaffold enhances the differentiation of EnSCs into endothelial lineage and increased VEGF expression suggesting a beneficial role of BG for angiogenesis in myocardial tissue engineering. 


\section{Acknowledgments:}

We thank the Iran National Science Foundation (INSF) for the financial support (grant number 91042417) and Tehran University of Medical Sciences for this research.

\section{References:}

[1] M.-J. Goumans, T.P. de Boer, A.M. Smits, L.W. van Laake, P. van Vliet, C.H.G. Metz, et al., TGF- $\beta 1$ induces efficient differentiation of human cardiomyocyte progenitor cells into functional cardiomyocytes in vitro, Stem Cell Res. 1 (2008) 138-149. doi:10.1016/j.scr.2008.02.003.

[2] G. Camci-Unal, N. Annabi, M.R. Dokmeci, R. Liao, A. Khademhosseini, Hydrogels for cardiac tissue engineering, NPG Asia Mater. 6 (2014) e99. doi:10.1038/am.2014.19.

[3] L.R. Madden, D.J. Mortisen, E.M. Sussman, S.K. Dupras, J.A. Fugate, J.L. Cuy, et al., Proangiogenic scaffolds as functional templates for cardiac tissue engineering, Proc. Natl. Acad. Sci. 107 (2010) 15211-15216. doi:10.1073/pnas.1006442107.

[4] M. Peter, N.S. Binulal, S.V. Nair, N. Selvamurugan, H. Tamura, R. Jayakumar, Novel biodegradable chitosan-gelatin/nano-bioactive glass ceramic composite scaffolds for alveolar bone tissue engineering, Chem. Eng. J. 158 (2010) 353-361. doi:10.1016/j.cej.2010.02.003.

[5] A.A. Gorustovich, J.A. Roether, A.R. Boccaccini, Effect of Bioactive Glasses on Angiogenesis: A Review of In Vitro and In Vivo Evidences, Tissue Eng. Part B Rev. 16 (2010) 199-207. doi:10.1089/ten.teb.2009.0416.

[6] R.M. Day, A.R. Boccaccini, S. Shurey, J.A. Roether, A. Forbes, L.L. Hench, et al., Assessment of polyglycolic acid mesh and bioactive glass for soft-tissue engineering scaffolds, Biomaterials. 25 (2004) 5857-5866. doi:10.1016/j.biomaterials.2004.01.043.

[7] H. Keshaw, A. Forbes, R.M. Day, Release of angiogenic growth factors from cells 
encapsulated in alginate beads with bioactive glass, Biomaterials. 26 (2005) 4171-4179. doi:10.1016/j.biomaterials.2004.10.021.

[8] R. Li, MD, PhD, Cardiomyocyte Transplantation Improves Heart Function, Ann. Thorac. Surg. 62 (1996) 654-661. doi:10.1016/S0003-4975(96)00389-X.

[9] G.Y. Koh, M.G. Klug, M.H. Soonpaa, L.J. Field, Differentiation and long-term survival of C2C12 myoblast grafts in heart., J. Clin. Invest. 92 (1993) 1548-1554. doi:10.1172/JCI116734.

[10] X. Li, X. Yu, Q. Lin, C. Deng, Z. Shan, M. Yang, et al., Bone marrow mesenchymal stem cells differentiate into functional cardiac phenotypes by cardiac microenvironment, J. Mol. Cell. Cardiol. 42 (2007) 295-303. doi:10.1016/j.yjmcc.2006.07.002.

[11] C.M. Raynaud, N. Halabi, D.A. Elliott, J. Pasquier, A.G. Elefanty, E.G. Stanley, et al., Human Embryonic Stem Cell Derived Mesenchymal Progenitors Express Cardiac Markers but Do Not Form Contractile Cardiomyocytes, PLoS One. 8 (2013) e54524. doi:10.1371/journal.pone.0054524.

[12] N.A.M. Bax, M.H. van Marion, B. Shah, M.-J. Goumans, C.V.C. Bouten, D.W.J. van der Schaft, Matrix production and remodeling capacity of cardiomyocyte progenitor cells during in vitro differentiation, J. Mol. Cell. Cardiol. 53 (2012) 497-508. doi:10.1016/j.yjmcc.2012.07.003.

[13] P.H. Carvalho, A.P.F. Daibert, B.S. Monteiro, B.S. Okano, J.L. Carvalho, D.N.Q. da Cunha, et al., Diferenciação de células-tronco mesenquimais derivadas do tecido adiposo em cardiomiócitos, Arq. Bras. Cardiol. 100 (2013) 82-89. doi:10.1590/S0066782X2012005000114.

[14] Y. Yoshida, S. Yamanaka, iPS cells: A source of cardiac regeneration, J. Mol. Cell. Cardiol. 50 (2011) 327-332. doi:10.1016/j.yjmcc.2010.10.026.

[15] X. Du, Q. Yuan, Y. Qu, Y. Zhou, J. Bei, Endometrial Mesenchymal Stem Cells Isolated 
from Menstrual Blood by Adherence, Stem Cells Int. 2016 (2016) 1-8. doi:10.1155/2016/3573846.

[16] K. Zheng, A. Solodovnyk, W. Li, O.M. Goudouri, C. St??hli, S.N. Nazhat, et al., Aging time and temperature effects on the structure and bioactivity of gel-derived $45 \mathrm{~S} 5$ glassceramics, J. Am. Ceram. Soc. 98 (2015) 30-38. doi:10.1111/jace.13258.

[17] Q.L. Loh, C. Choong, Three-dimensional scaffolds for tissue engineering applications: role of porosity and pore size., Tissue Eng. Part B. Rev. 19 (2013) 485-502. doi:10.1089/ten.TEB.2012.0437.

[18] M. Haeri, M. Haeri, ImageJ Plugin for Analysis of Porous Scaffolds used in Tissue Engineering, J. Open Res. Softw. 3 (2015) 2-5. doi:10.5334/jors.bn.

[19] S. Ebrahimi-barough, Differentiation of Human Endometrial Stromal Cells into Oligodendrocyte Progenitor Cells (OPCs), (n.d.). doi:10.1007/s12031-013-9957-z.

[20] O. Bretcanu, X. Chatzistavrou, K. Paraskevopoulos, R. Conradt, I. Thompson, A.R. Boccaccini, Sintering and crystallisation of $45 \mathrm{~S} 5$ Bioglass ${ }^{\circledR}$ powder, J. Eur. Ceram. Soc. 29 (2009) 3299-3306. doi:10.1016/j.jeurceramsoc.2009.06.035.

[21] Q.Z. Chen, I.D. Thompson, A.R. Boccaccini, 45S5 Bioglass ${ }^{\circledR}$-derived glass-ceramic scaffolds for bone tissue engineering, Biomaterials. 27 (2006) 2414-2425. doi:10.1016/j.biomaterials.2005.11.025.

[22] K. Xie, L. Zhang, X. Yang, X. Wang, G. Yang, L. Zhang, et al., Preparation and Characterization of Low Temperature Heat-Treated 45S5 Bioactive Glass-Ceramic Analogues, Biomed. Glas. 1 (2015) 80-92. doi:10.1515/bglass-2015-0008.

[23] E. Sharifi, M. Azami, A.-M. Kajbafzadeh, F. Moztarzadeh, R. Faridi-Majidi, A. Shamousi, et al., Preparation of a biomimetic composite scaffold from gelatin/collagen and bioactive glass fibers for bone tissue engineering, Mater. Sci. Eng. C. 59 (2016) 533-541. doi:10.1016/j.msec.2015.09.037. 
[24] V.Y. Birshtein, V.M. Tul'chinskii, A study of gelatin by IR spectroscopy, Chem. Nat. Compd. 18 (1982) 697-700. doi:10.1007/BF00579426.

[25] J.. Muyonga, C.G.. Cole, K.. Duodu, Fourier transform infrared (FTIR) spectroscopic study of acid soluble collagen and gelatin from skins and bones of young and adult Nile perch (Lates niloticus), Food Chem. 86 (2004) 325-332. doi:10.1016/j.foodchem.2003.09.038.

[26] M. Mačković, A. Hoppe, R. Detsch, D. Mohn, W.J. Stark, E. Spiecker, et al., Bioactive glass (type 45S5) nanoparticles: in vitro reactivity on nanoscale and biocompatibility, J. Nanoparticle Res. 14 (2012) 966. doi:10.1007/s11051-012-0966-6.

[27] V. Mourino, J.P. Cattalini, A.R. Boccaccini, Metallic ions as therapeutic agents in tissue engineering scaffolds: an overview of their biological applications and strategies for new developments, J. R. Soc. Interface. 9 (2012) 401-419. doi:10.1098/rsif.2011.0611.

[28] E. Sharifi, S. Ebrahimi-Barough, M. Panahi, M. Azami, A. Ai, Z. barabadi, et al., In vitro evaluation of hEnSCs derived osteoblast like cells behavior on gelatin/collagen/bioglass nanofibers scaffolds, J. Biomed. Mater. Res. Part A. (2016) 110. doi:10.1002/jbm.a.35748.

[29] A. Shamosi, D. Mehrabani, M. Azami, S. Ebrahimi-Barough, V. Siavashi, H. Ghanbari, et al., Differentiation of human endometrial stem cells into endothelial-like cells on gelatin/chitosan/bioglass nanofibrous scaffolds, Artif. Cells, Nanomedicine, Biotechnol. (2016) 1-11. doi:10.3109/21691401.2016.1138493.

[30] A. Shamosi, M. Farokhi, J. Ai, E. Sharifi, Induction of spontaneous neo-angiogenesis and tube formation in human endometrial stem cells by bioglass, J. Med. Hypotheses Ideas. 9 (2015) 94-98. doi:10.1016/j.jmhi.2015.09.004.

[31] C. Bowes Rickman, M.M. LaVail, R.E. Anderson, C. Grimm, J. Hollyfield, J. Ash, eds., Retinal Degenerative Diseases, Springer International Publishing, Cham, 2016. 
doi:10.1007/978-3-319-17121-0.

[32] L.L. Fernandes, C.X. Resende, D.S. Tavares, G.A. Soares, L.O. Castro, J.M. Granjeiro, Cytocompatibility of chitosan and collagen-chitosan scaffolds for tissue engineering, Polímeros. 21 (2011) 1-6. doi:10.1590/S0104-14282011005000008.

[33] M. Fayazi, M. Salehnia, S. Ziaei, Differentiation of human CD146-positive endometrial stem cells to adipogenic-, osteogenic-, neural progenitor-, and glial-like cells, Vitr. Cell. Dev. Biol. - Anim. 51 (2015) 408-414. doi:10.1007/s11626-014-9842-2.

[34] T. Hao, N. Wen, J.-K. Cao, H.-B. Wang, S.-H. Lü, T. Liu, et al., The support of matrix accumulation and the promotion of sheep articular cartilage defects repair in vivo by chitosan hydrogels., Osteoarthritis Cartilage. 18 (2010) 257-65. doi:10.1016/j.joca.2009.08.007.

[35] M. Rahimi, A.-H. Zarnani, H. Mohseni-Kouchesfehani, H. Soltanghoraei, M.-M. Akhondi, S. Kazemnejad, Comparative Evaluation of Cardiac Markers in Differentiated Cells from Menstrual Blood and Bone Marrow-Derived Stem Cells In Vitro, Mol. Biotechnol. 56 (2014) 1151-1162. doi:10.1007/s12033-014-9795-4.

[36] Q. Qian, H. Qian, X. Zhang, W. Zhu, Y. Yan, S. Ye, et al., 5-Azacytidine Induces Cardiac Differentiation of Human Umbilical Cord-Derived Mesenchymal Stem Cells by Activating Extracellular Regulated Kinase, Stem Cells Dev. 21 (2012) 67-75. doi:10.1089/scd.2010.0519.

[37] A.M. Smits, P. van Vliet, C.H. Metz, T. Korfage, J.P. Sluijter, P.A. Doevendans, et al., Human cardiomyocyte progenitor cells differentiate into functional mature cardiomyocytes: an in vitro model for studying human cardiac physiology and pathophysiology, Nat. Protoc. 4 (2009) 232-243. doi:10.1038/nprot.2008.229. 


\section{Figure captions:}

Figure1- FTIR spectrum of fabricated scaffolds

Figure 2: MTT assay of Cell proliferation and viability on GEL/COL and GEL/COL/BG scaffolds 24, 48 and $72 \mathrm{~h}$ following cell seeding. * indicated with $\mathrm{P}$ value $<0.05$

Figure 3- SEM micrographs of scaffolds (above), SEM images of cells on scaffolds (middle) and Nuclei staining of cells grown on scaffolds 15 days post cell seeding (below); [Gel/Col (A), Gel/Col/BG (B)]

Figure 4- Morphological characterization of cardiomyocytes derived from EnSCs (b, c, d) 4weeks post differentiation compared to undifferentiated EnSCs (a)

Figure 5- ICC staining for cardiac proteins $\alpha$ - actinin, TnT, Con43 and Desmin, 28 days post 5aza treatment. Nuclei are stained with dapi.

Figure6- ICC staining for MYOD and CD31, 28 days post 5aza-cytidine treatment. Nuclei stained with dapi.

Figure 7: Relative gene expression for cardiac specific genes in 2D treated cells versus to untreated cells using real-time PCR. *, $\mathrm{P} \leq 0.05$ and $* *, \mathrm{P} \leq 0.01$

Figure 8: Relative gene expression for cardiac specific genes in cells cultured on both scaffolds compared to $2 \mathrm{D}$ treated cells as control using real-time PCR

Figure 9: IHC for cardiac protein $\alpha$ - actinin and CD31 for cells grown on GEL/COL scaffold (Left column)and GEL/COL/BG scaffold (Right column) 


\section{Tables:}

Table 1: The primer sequences used for real time PCR

\begin{tabular}{|c|c|c|c|c|}
\hline GENE & Accession no. & Primer & $\begin{array}{c}\text { Primer } \\
\text { length (bp) }\end{array}$ & $\begin{array}{l}\text { Amplicon } \\
\text { length }\end{array}$ \\
\hline GAPDH & NM_002046.3 & $\begin{array}{l}\text { F-5'ACATCATCCCTGCCTCTACTG3' } \\
\text { R-5'CCTGCTTCACCACCTTCTTG3' }\end{array}$ & $\begin{array}{l}21 \\
20\end{array}$ & 180 \\
\hline cTnT & NM_000364.3 & $\begin{array}{l}\text { F-5'GCGGGAAGGCTAAAGTCAC3' } \\
\text { R-5'TGGTGTGGAGTGGGTGTG3' }\end{array}$ & $\begin{array}{l}19 \\
18\end{array}$ & 206 \\
\hline$\alpha$ ACTININ & NM_005159.4 & $\begin{array}{l}\text { F-5'GATGTATGTGGGTCTGGGTCTTAG3' } \\
\text { R-5'TGTCTTGTATCCTGGCTTCTGC3' }\end{array}$ & $\begin{array}{l}24 \\
22\end{array}$ & 109 \\
\hline DESMIN & NM_001927.3 & $\begin{array}{l}\text { F-5'CCGTGGTCTCTTACTTTCCTTTC3' } \\
\text { R-5'CTTTCTCTCCTTCTCAATCTCCTG3' }\end{array}$ & $\begin{array}{l}23 \\
24\end{array}$ & 116 \\
\hline MHC & NM_002471.3 & $\begin{array}{l}\text { F-5'AGAACCAGTCCATCCTCATCAC3' } \\
\text { R-5'TTCGCATTGGCATTGTCCTTC3' }\end{array}$ & $\begin{array}{l}22 \\
21\end{array}$ & 130 \\
\hline
\end{tabular}


Table2- Peak assignments of Gel/Col and BG/Gel/Col FTIR

\begin{tabular}{|c|c|c|}
\hline \multirow{2}{*}{ Peak assignments } & \multicolumn{2}{|c|}{ Wave numbers $\left(\mathrm{Cm}^{-1}\right)$} \\
\hline & Gel/Col/BG & Gel/Col \\
\hline Amid $\mathrm{A}$ band $\mathrm{N}=\mathrm{H}$ stretching Vibration & 3403 & 3413 \\
\hline Peptide NH group & 3265 & 3285 \\
\hline Amid B band asymmetrical stretch of $\mathrm{CH} 2$ & 3055 & 3066 \\
\hline Amide $\mathrm{B}$, asymmetrical stretch of $\mathrm{CH}_{2}$ & 2920 & 2929 \\
\hline Amide I band stretching vibrations of the & 1625 & 1631 \\
\hline \multicolumn{3}{|l|}{ carbonyl groups $(\mathrm{C}=\mathrm{O})$ bond } \\
\hline Amide II N -H bending vibration coupled with & 1527 & 1537 \\
\hline \multicolumn{3}{|l|}{$\mathrm{CN}$ stretching vibration } \\
\hline Amide III & 1437 & 1448 \\
\hline Amide I peak associated with the triple-helical & 1227 & 1230 \\
\hline structure 1 & & \\
\hline
\end{tabular}

